\title{
Exploring first-year undergraduates' perceptions of poetry and their acquisition of skills in reading poetry for study at university
}

Daniel Weston

University of Greenwich

\begin{abstract}
There is significant evidence drawn from student evaluations that students embarking on undergraduate English degrees feel uneasy about studying poetry and that this anxiety has an effect on the module choices they make as they progress through the three years of their programme. This study aims to investigate the causes of students' responses to poetry and to make a beginning in looking at the implications that this has for teaching and learning. It explores students' acquisition of skills and attitudes that make poetry-reading a rewarding activity. Data has been gathered from focus groups with first-year undergraduate students in an English department at a UK university to discover what perceptions of poetry students hold and what factors in teaching contribute to the development and/or perpetuation of these perceptions. In brief, the study finds that, for effective teaching, the cultivation of enthusiasm for poetry is just as important as building technical vocabulary and learning techniques of formal analysis. There is some evidence that the technical competence flows out of enthusiasm. The study also finds that students feel their enjoyment of and affective response to poetry is often overlooked in the classroom.
\end{abstract}

\section{Introduction}

The initial motivation to research the teaching of poetry to first-year undergraduates arose from anecdotal experience in my own teaching at several UK higher education (HE) institutions; I came to believe that first-year undergraduate students enrolled on English degree programmes feel less comfortable studying poetry than prose (for example, novels or short stories), are less willing to engage in seminar discussion of poetry and choose to write assessed essays on it less often than on other literary forms. Informal discussion with colleagues revealed to me that others engaged in teaching these subjects had similar experiences. Basic analysis of students' choices provides some good backing for this anecdotal evidence. For this purpose, I draw on data relating to a compulsory, core module for all single and joint honours students on BA programmes in English at a UK university. Assessment on the course permits students to select an essay question from a list of options (with their choice having no bearing on future choices available to them and therefore being a reasonably reliable indication of their preferences). Even though roughly $50 \%$ of the texts available for the students to choose from were poetry, only $20 \%$ chose to write on poetry, with the figure dropping further to $8 \%$ for modern poetry (defined as that written in the twentieth and twenty-first centuries). When cohorts reach second- and third-year study, their selection of option modules reveals a similar trend: modules involving little or no study of poetry recruit larger numbers of students than those focused primarily on poetry. Of course, there are other variables to take into account here, but the trend seems to be significant nonetheless. Combining anecdotal evidence and these figures reveals a fairly consistent cohort division: a few students elect to study poetry whenever they can, whilst most, where possible, avoid it. As second- and third- year preferences tend to follow those established in 
the first year (or earlier), it may be the case that formative engagements with poetry in the HE setting are important in determining which of these groups students subsequently fall into.

This study explores first-year English students' perceptions of poetry and investigates what factors in teaching cultivate and perpetuate these perceptions. I am particularly interested in determining what kinds of teaching have led students to feel that they have made significant progress in understanding and enjoying poetry. I am also interested in where students feel that they have experienced difficulties and what types of instruction they have found to be less productive. I conclude by making recommendations for practice in the undergraduate teaching of poetry. I feel that this guidance is particularly necessary because, whilst many academics who teach in English departments have to teach poetry, their research expertise might be focused on a different area of literature. They might not have studied poetry in any detail since they themselves were undergraduate students.

\section{Literature review}

The teaching of poetry, along with other forms of literature, has been conditioned by the changes that have accompanied the growth of English as an academic subject over a long period. The model for the study of English that held sway from the 1920s to the 1960s and beyond is that of new criticism, as developed by F.R. Leavis (1952) and others. This mode of engagement with literature saw the literary critic and the student of literature as arbiters of culture and tradition, equipped with the skills of close reading in order to discern valuable thought of use to society and to confirm the greatness of canonical literature (Leavis, 1952). The methodology that grew up around this aim was the identification of the literary features that bespoke the poem's or the novel's quality, along with a vocabulary to articulate this. The unspoken rationale underlying this method is that terminology underpins communities of practice (Wenger, 1998). Amongst the multiple challenges to this way of thinking that have subsequently taken place, the growth of reader response theory is the most significant for classroom teaching and learning. Across the 1970 s and ' 80 s, reader response theory sought to shift emphasis away from the 'Leavisite' mode and to focus instead on how readers actually experience a poem and engage with it (Rosenblatt, 1970, 1978; Iser, 1978, 1988).

These changes led Dias and Hayhoe (1988, p.5). to argue that traditional English teaching in schools had focused too much on identifying and accounting for features: "The apprehension of a poem as a process of close reading, a careful attending to the words on the page, an 'explication' ... has led to classes in poetry where the sole object is one of training pupils to read poetry by examining as many aspects as would explain its inner workings". This critique then made space for the development of 'progressive' English teaching, such as Cox's 'personal growth' model, focusing on the role of poetry in "developing children's imaginative and aesthetic lives" (Cox, 1991, p.21), and John Dixon's suggestion that "English is about finding personal and social experiences worth sharing, and in the course of doing so, potentially making discoveries" (Dixon, 2009, p.244). More specifically, Naylor and Wood (2012, p.viii), again focusing on school rather than university teaching, recommend "mov[ing] away from a model of teaching poetry from the front, where the teacher explains meanings that pupils passively accept, to an active approach where pupils are able to access the ideas behind the poetry, enabling them to make their own meanings and respond to the poetry on a personal level". However, at a more advanced level of study, the situation is less clear. For Knapp (2002, p.720), questions remain for the 
college and university teacher: "How does one induct a novice reader into an interpretive community of developed expertise? What specific steps does one take to move novice literati from relative ignorance to readerly sophistication?" In the very phrasing of Knapp's query, the tension between the two models for studying literature - Leavisite and reader response - remains unresolved. A further question that is also necessary to ask (but that Knapp does not ask) is: How does one enthuse and motivate a student to want to enter this interpretive community?

To survey student-targeted introductory guides and primers in the study of poetry is to find that focus is often devoted to the technical aspects of writing in verse and to providing the associated specialist vocabulary for talking and writing about them. Three examples demonstrate prevailing trends in study guides aimed at undergraduates. John Lennard's The

\section{Poetry Handbook: A Guide to Reading Poetry for Pleasure and Practical Criticism}

(Lennard, 2005: p.xxi) is paradigmatic in aiming to provide readers "with a better understanding of craft and technique' such that they might 'judge' a poem and poet". Thus, the book "introduces students to the technical vocabulary of poetry and its criticism". This vocabulary "though perhaps off-putting, is essential" (op.cit., p.xxiv). The book is written against the view that "analysis spoils pleasure" and out of the conviction that "understanding redoubles pleasure" (ibid., p.xxv). As a result, it takes the form of a series of chapters devoted to poetic devices (metre, form, layout, rhyme, etc.). Each chapter ends with a discussion of the feature under consideration in Derek Walcott's poem 'Nearing Forty'. Despite this concession to engaging with a particular poem, the focus is firmly on technical information, even though there is an open acknowledgement that is felt to be off-putting by many students.

\section{Like Lennard's book, Rhian Williams's The Poetry Toolkit: The Essential Guide to}

Studying Poetry (Williams, 2009, p.8) aims to "explore and explain the technical vocabulary often used in studying poetry". It, too, gives over the bulk of its content to chapters dealing with forms, prosody, rhyme, stanzas, etc. Like Lennard, Williams is also conscious that "technical vocabulary and poetic devices can be off-putting", but proceeds with this focus nonetheless (op. cit., p.4). Shira Woloksky's The Art of Poetry: How to Read a Poem (Woloksky, 2001) is also organised into chapters focusing on technicalities - individual words, syntax and poetic line, images, simile and metaphor, etc. - even though it focuses less obviously on specialist vocabulary and does take on more extended examples.

There is, however, an alternative methodology (one that implicitly draws on reader response theory) discernible in other books that introduce or otherwise approach the topic but are not presented primarily as study guides for undergraduate students (as the three samples above are). Tom Paulin's The Secret Life of Poems: A Poetry Primer takes the form of an anthology of forty poems with Paulin's commentaries on them - typically two or three pages in length on each - with no introductory essay. The only front matter of any note is a onepage entry on metrical feet and consonants (Paulin, 2008, p.ix). Even here, definitions are not offered; instead, there is a single example of each type of poetic foot (e.g. iamb, trochee) and the different consonant sounds listed in their classes (e.g. aspirant, fricative). The point is that, even when technical information is being conveyed, the choice has been made to do so via tangible example rather than theoretical discussion. As the back-cover blurb makes clear, "Paulin attends closely to the words on the page, above all their hidden acoustic and 
musical workings". That is, the focus is still on technical aspects but by a completely different means.

Ruth Padel's 52 Ways of Looking at a Poem: A Poem for Every Week of the Year takes a similar approach to Paulin's, with a body of poetry accompanied by short commentaries. Here too, the focus is on engaging with particular poems and, as the title suggests, doing so regularly and in sustained ways. Familiarity is the key. Padel (2004, p.4) avers that "the important thing is making your own relationship with the poem". "You can respond to a poem emotionally and imaginatively without being aware of the technical ways it gets its effects", and in that process your interest may lead you to seek out that technical understanding. Thus, "with poems, technical illumination increases your enjoyment in something that was, after all, made for you" (op.cit., p.5). It is not the case then that technical vocabulary is absent here, but that it is arrived at through reading poems, rather than undergoing the offputting prelude to that enjoyable engagement as it might be in Lennard, Williams and, to a lesser extent, Woloksky. A final example cements the difference. John Fuller's Who Is Ozymandias? And Other Puzzles in Poetry "is intended to comfort readers who find poetry difficult by showing that everyone, including professional critics, can find it difficult. ... Poetry is a form of writing that deliberately employs puzzles as a means of engaging the reader in the pleasurable business of solving them, and that therefore we might as well take our time". The book "is largely built, not so much on theories about all this, but on a number of briefly considered examples of individual puzzles" (Fuller, 2011, p.vii). Once again, the focus is on pleasure in reading as the means by which to build understanding. Paulin, Padel and Fuller are all still attempting to equip readers to enter the 'interpretive community' that Knapp identifies, whilst not putting them off with technical vocabulary as a prerequisite. It may be worth noting here that these three are themselves well-regarded poets and therefore bring a different set of experiences and understandings (especially those won outside the classroom) to this endeavour. My research looks to ascertain whether this approach might solve some of the problems in enthusing undergraduate students of poetry identified at the outset of this paper.

\section{Investigation methodology}

This project falls under Norton's definition of pedagogical action research, as I am a practitioner within the field of poetry teaching rather than an outsider, and because the study has "the dual aim of modifying practice and contributing to theoretical knowledge" (Norton, 2008, p.xvi). This is a qualitative, interpretivist study that relies on rich student data from a relatively small sample, in order to allow for good depth of analysis rather than comprehensive breadth of coverage. It selects focus groups over other forms of interview as the means of gathering data so that "the participants rather than the researcher's agenda can predominate" (Cohen et al., 2011, p.436).

My aim was to reduce as far as possible my own influence on the results. I followed Fowler's recommendation of six to eight participants in each group so that each participant could contribute fully (Fowler, 2009, p.117). In order to achieve this number, I over-recruited (calling on ten participants per group) to allow for the twenty per cent non-attendance that Morgan (1997, p.44) suggested might be expected. In this study, Morgan's prediction for attendance rates proved accurate. I used three different groups in an attempt to ensure that findings could be generalised rather than relate only to one particular group and in the hope 
that this would avoid any skewing of data by the dominance of one voice within a group (Morgan, op.cit; Smithson, 2000).

I designed the method of conducting the focus groups with the aim of capturing students' perspectives: they were semi-structured, with some basic questions, but without a rigorously-upheld agenda, allowing for probing into certain points to gather greater detail and encouraging participants to talk to one another, rather than through the researcher, as much as possible. To this end, the initial questions were very open:

- Have you enjoyed your encounters with poetry? Why/why not?

- What helped you in overcoming any difficulties you experienced?

- Has studying poetry at university been similar to/different from at school/college? How?

- Have you found particular books useful?

As Norton (op.cit., p.74) suggests, features such as these are "much more likely to establish a richer picture of the student perspective". I also chose the methods of data collection to encourage participants to set their own agenda. Thus, in addition to the audio-recording that is standard practice in focus groups, I provided flip charts and pens for participants to record and organise in their own terms what they felt to be important. This extra source of collaboratively-produced data was then triangulated with others to corroborate the important themes and issues.

I decided upon the identification of a group from which to draw participants with the aim of accessing responses from those for whom the first experience of studying poetry at university was a recent experience and fresh to mind. I therefore targeted first-year students, rather than second- and third-year, as the latter groups' memories of initial engagements with poetry at university might not be so easily recalled. Data from first years might prove more reliable because of this factor. Students enrolled on a core first-year module covering a range of literature, including poetry, were invited to take part. This sample was therefore broad and had experience of the issue being investigated. All students on the module were invited to participate, apart from those whom I taught personally; I avoided inclusion of these students to prevent the possibility of any perception of a personal power position in this activity. I selected and assigned those who were willing to take part to groups - this by student number rather than name to eliminate possible bias. All participants' contributions were anonymised to ensure confidentiality. All were given and signed an informed consent form.

\section{Results, analysis and interpretation}

Following Glesne's guidance for data analysis (2011), I thought it necessary to present the interpretations on the basis of thematic analysis, since what had initially seemed a rudimentary coding process became, when in contact with the data, increasingly complex. In effect, this means that I applied, on the one hand, a blend of a priori 'template' codes and, on the other, codes developed through encounter with the data. In the light of Morgan's assertion (1997, p.62) that "those who can answer their research questions without counting codes should feel well justified in doing so", I do not present statistics here. Rather, I describe the points on which there was broad consensus in focus-group discussions and the themes that emerged as significant. The importance of particular topics and views has been 
determined by a combination of factors: how many groups mentioned something, how many participants within a group mentioned it and how much energy was generated in discussing it.

Focus groups' discussions revealed a broad consensus on a number of points, but some disparity on others. The first point of consensus was that practical classroom experience of working with particular poems was felt to be important in understanding poetry. For example, one participant reported: "it being like a different poem after we worked on it in class"; another said that "it just clicked once we'd gone through it together". A number of participants across all three groups contrasted this against similar activity undertaken alone in private study ("I didn't get it before"; "I couldn't get anything like as far on my own"). The only detractors from this consensus were those who also reported already enjoying reading and analysing poetry before degree-level study. Discussion of poems was generally seen both as crucial to understanding and enjoyable. Adding nuance to this broad finding, some participants reported that hearing a range of interpretations of a poem from their peers in seminars was a positive experience. Reasons for this varied from feeling that "there's no right answer but a lot of options" to "it made it more free". A related finding was that learning about poetry was mentioned far more often in conjunction with seminars than with lectures.

The issue of vocabulary and technical analysis of poems was often mentioned. This was discussed negatively by participants who also reported not enjoying the study of poetry. Such a correlation suggests that technical vocabulary can indeed be off-putting for students. However, almost all reported recognising the importance of "knowing the right terms" (including those who struggled with that). Participants were more positive about technical vocabulary when used with reference to specific examples. In this context, "it made sense", whereas, without locating the technical terms in examples, it "felt like doing maths". The combination of these two points - preference for classroom study of particular poems and dislike for technical vocabulary in abstract contexts - carries clear implications. These focus groups suggested that students are most enthused by hands-on learning through example when it comes to initial engagements with poetry in HE. They realise that vocabulary is important, but feel better equipped to use it when they have tangible examples to focus on. This finding clearly speaks to the issues raised in the literature review.

Other points that emerged open up new considerations. There was significant consensus on how it felt to learn about poetry: many participants, again across all three groups, reported experiencing a moment in which understanding was arrived at suddenly rather than via a patient accumulation ("it was like eureka"; "it just clicked"). It is less obvious how instructors might capitalise on knowing this and cultivate such moments in the classroom. The opposite is true of one other aspect of teaching. Many participants reported that hearing poems read aloud revealed a lot to them about their workings and aided their understanding (though some did not like to read poems aloud to the class themselves). It is clear that for participants in these focus groups this activity is a very worthwhile one.

Lastly, participants were less interested in discussing the issue of similarities/differences between poetry teaching at university and that experienced previously at school or college. Neither was much attention devoted to the question of whether particular books had been helpful, even when prompted. Data on these questions does not provide much information towards a consensus. 
The provision of flip charts and pens for participants to record their ideas did not produce any data radically different from that gathered via audio-recording, but it did allow for a clearer sense of what the most important points were for participants. These were twofold: firstly, learning about poetry is facilitated best by classroom discussion of particular poems; secondly, learning about technical aspects and being able to apply appropriate vocabulary is recognised to be necessary, is found difficult by a significant proportion of students and is made easier when linked to the reading of the poems in question.

\section{Conclusions}

It is clear that, for participants in these focus groups, what makes students feel most comfortable in learning about poetry when they first encounter it at university conflicts with the ways that some textbooks implicitly and explicitly recommend that they ought to learn about it (Lennard, op.cit; Williams, op.cit.). Whilst students recognise the importance of the information that will allow them to express their thoughts on poetry in academic terms (and sometimes recognise that this actually opens up new possibilities), they do not feel that this information is always effectively packaged for them to absorb. Spending more time on specific examples - that is, particular poems - and less on the 'rules' of poetry analysis in the abstract is likely to achieve students' acquisition of the appropriate critical vocabulary and a working understanding of it - and at the same time to foster their enthusiasm for the endeavour. The benefit of the latter is significant. Extended focus on examples and the more thorough engagement that this encourages also make more likely the 'eureka' moment that some participants reported occurring. It is also clear that participants felt reading poems aloud to be a valuable activity that enhanced their understanding of how the verse functioned. The literary devices that poets deploy are perhaps made more explicit when they are heard in action. It is also reasonable to assume both that students are unlikely to read poems aloud to themselves in private study and that lectures and seminars (especially the latter) are the learning situations in which reading aloud could most productively be employed.

\section{Evaluation of the study}

Clearly, with comparatively small numbers of participants in focus groups, this project should be considered to be a pilot study rather than a full or complete piece of compelling research. Nevertheless, the findings that emerged are clear enough to suggest that a larger and more detailed treatment of the issues would be valuable. Future extension to the work could take up two different approaches. The first would be, simply, to increase the number of participants and the number of focus groups. More data of the same kind might make a more extensive and elaborate coding process rewarding. Statistical data would be more meaningful in this context. The second would be a triangulation of this kind of data with other sources of qualitative information. Triangulating this focus group material with a survey or other types of interview (that were not attempted here owing to constraints of time and resources) would help to build a more detailed picture from the sketch that I have provided.

This nature of this research has been part exploration and part hypothesis-testing. I began with anecdotal experience of the problem - students not enjoying the study of poetry as much as other literary forms and choosing it less often - that I wanted to explore and then built towards a sense of the possible reasons for this and the means to address it through the literature review that I undertook before beginning work with the focus groups. Given that 
the findings to emerge out of the focus groups broadly confirmed these indications, my own position in relation to this set of issues must be acknowledged. As an advocate of poetry with strong views about the subject, I cannot be considered a disinterested researcher regardless of the measures I put in place to guard against my influencing the results described above.

\section{Reference list}

Cohen, L. Manion, L. and Morrison K. (2011) Research Methods in Education, $7^{\text {th }}$ edition. Abingdon: Routledge.

Cox, B. (1991) Cox on Cox: An English curriculum for the 1990s. London: Hodder and Stoughton.

Dias, P. and Hayhoe, M. (1988) Developing Response to Poetry. Oxford: Oxford University Press.

Dixon, J. (2009) English renewed: visions of English among teachers of 1966. English in Education, 43(3), 241-50.

Fowler, F.J. Jr. (2009) Survey Research Methods, 4th edition. Thousand Oaks, CA: Sage.

Fuller, J. (2011) Who is Ozymandias? And Other Puzzles in Poetry. London: Vintage.

Glesne, C. (2011) Becoming Qualitative Researchers: An Introduction, 4th edition. Boston, MA: Pearson.

Iser, W. (1978) The Act of Reading: A Theory of Aesthetic Response. London: Routledge.

Iser, W. (1988) The reading process; a phenomenological approach. In: Lodge, D. and Wood, N. (eds), Modern Criticism and Theory. Edinburgh: Pearson, 295-310.

Knapp, J. (2002) Teaching Poetry via HEl (Hypothesis-Experiment-Instruction). Journal of Adolescent \& Adult Literacy, 45(8), 718-729.

Leavis, F.R. (1952) The Common Pursuit. London: Chatto \& Windus.

Lennard, J. (2005) The Poetry Handbook: A Guide to Reading Poetry for Pleasure and Practical Criticism, 2nd edition. Oxford: Oxford University Press.

Morgan, D.L. (1997) Focus Groups as Qualitative Research, 2nd edition. Beverley Hills, CA: Sage.

Naylor, A. and Wood, A.B. (2012) Teaching Poetry: Reading and responding to poetry in the secondary classroom. Abingdon: Routledge.

Norton, Lin S. (2008). Action Research in Teaching and Learning. Abingdon: Routledge.

Padel, R. (2004) 52 Ways of Looking at a Poem: A Poem for Every Week of the Year. London: Vintage. 
Paulin, T. (2008) The Secret Life of Poems: A Poetry Primer. London: Faber.

Rosenblatt, L. (1970) Literature as Exploration. London: Heinemann.

Rosenblatt, L. (1978) The Reader, the Text and the Poem. Carbondale and Edwardsville: Southern Illinois University Press.

Smithson, J. (2000) Using and analyzing focus groups: limitations and possibilities. International Journal of Social Research Methodology, 3(2), 103-19.

Wenger, E. (1998) Communities of Practice: Learning, Meaning and Identity. Cambridge: Cambridge University Press.

Williams, R. (2009) The Poetry Toolkit: The Essential Guide to Studying Poetry. London: Continuum.

Woloksky, S. (2001) The Art of Poetry: How to Read a Poem. Oxford: Oxford University Press. 